\title{
Comparison of Two Approaches for Estimation of Genetic Variation for Two Economic Traits in Faba Bean Genotypes Grown under Waterlogged Verisols
}

\author{
Gemechu Keneni* and Musa Jarso
}

Holetta Agricultural Research Center, P.O.Box 2003, Addis Abeba, Ethiopia.

\begin{abstract}
There is little experimental evidence about whether component of variance calculated from separate analysis of variance in waterlogged conditions is effective in estimating the extent of heritable variation and the effectiveness of selection. Seven faba bean variety trials consisting of 17-25 different genotypes each were conducted at four locations in lattice or RCB designs with 2 or 3 replications on drained (using broad bed and furrow, BBF) and undrained (flatbeds) Vertisols between 1996 and 1999. Records on 1000 seed weight and grain yield were subjected to statistical analyses using SAS computer software. Grain yield was more sensitive to waterlogging stress than 1000 seed weight. Heritability and expected genetic gains calculated from separate analysis were higher than those calculated from pooled analysis of variance for both grain yield and 1000 seed weight. The relative precision improvement of pooled analysis of variance over separate analysis ranged from $57-83 \%$ for grain yield and $7-25 \%$ for thousand seed weight. Thousand seed weight was more heritable than grain yield. There was weak association between heritability and expected genetic gains calculated from separate and pooled analyses of variance for grain yield and strong positive association for 1000 seed weight, indicating that genetic variation and effectiveness of selection for thousand seed weight could, more accurately, be calculated from separate analysis of variance than grain yield. Thus, studies on genetic variability and effectiveness of selection for grain yield based on separate analysis of variance could be misleading under both drained and waterlogged Vertisols because of the potential danger of wrong conclusions that could be drawn from the confounding effects of genotype by environmental interaction.
\end{abstract}

Keywords: Broad-Sense Heritability; Expected Genetic Gain; Genotypic Variation; Phenotypic Variation; Pooled Analysis of Variance; Separate Analysis of Variance

\section{Introduction}

Plant breeders use biometrical techniques to assess genetic variability among and within genotypes, to develop selection criteria, heterotic parents for hybridization, effective breeding procedures and varietal stability (Singh, 1990). Selection of superior genotypes across locations and thoughtout years is a complicated process as it is based on the phenotypic performances of genotypes and the phenotype is the result of not only genetic but also environmental and genotype by environment interaction. Estimation of genetic variation among genotypes is, therefore, the main concern of breeders as the effectiveness of selection depends on the proportion of the heritable variation, i.e. heritability. However, heritability per se is not sufficient to predict the effectiveness of selection unless it is considered along with expected genetic gain from selection (Allard, 1960). Environmental and genotype by environment interaction effects are not heritable and, hence, the higher the environmental and the genotype by environment interaction effects, the lower the level of success from selection.

The magnitude of components of variance is commonly calculated from the analysis of variance. It is generally believed that genotype by environment interaction arises from changes in genotypic performances over environment. Whether components of variances calculated from an evaluation of genotypes conducted at only one location for a season (separate analysis of variance) is effective for estimating the extent of heritable variation and the effectiveness of selection is a matter of some concern. A number of authors in
Ethiopia have based their analyses of components of variation in different crops on separate analysis of variance, particularly as part of thesis research (Gemechu, 1996, Gemechu et al., 1999; Tesfaye, 1999; Temesgen, 2002), including faba bean under waterlogged vertisols (Wondafrash, 2002). However, others argue that genotypic variances estimated in such a way are biased upward as they do not contain genotype by environment interaction variances (Singh, 1990) especially in a stressed environment where genotype by environment interaction is greater (Briggs and Knowles, 1967; Rosielle and Hamblin, 1981).

Grain yield and seed size are economic traits representing the first and the second priority as prime objectives of the Ethiopian faba bean breeding program (Asfaw et al., 1994). Among the target environments for specific breeding are the waterlogged vertisols of the highlands, where genotypes have been evaluated both in drained conditions (moderately stressed) using broad bed and furrow (BBF) and undrained flatbeds (highly stressed). In stressed conditions, where genotype by environment interaction is high, (Rosielle and Hamblin, 1981; Singh, 1990; Simmonds, 1991; Banziger and Edmeades, 1997), it is expected that evaluation of genotypes only at one location for a season may not be enough to determine genetic variation and the effectiveness of selection. However, there is little experimental evidence, not only in faba bean but also in several other crops, which supports most of these arguments. The objective of this study was, therefore, to determine the effectiveness of separate analysis of variance for estimating genetic variation and 
effectiveness of selection for grain yield and seed size compared to pooled analysis of variance in faba bean genotypes grown in drained and undrained vertisols.

\section{Materials and Methods}

Seven variety trials consisting of 17-25 different genotypes each were used in this study. The entries consisted of genotypes extracted from different germplasm collected from Ethiopia, a few introductions from ICARDA and local and improved cultivars. The trials were conducted at four locations (Ginchi, Enewari, Bichena and Sinja) in drained (BBF) and undrained (flatbed) vertisols between 1996 and 1999 (Table 1). The experiments were arranged either in lattice or RCB designs in 2 or 3 replications. Analysis of variance was made assuming RCBD in all the cases for simplicity. Management was undertaken as per the recommendation at each location. Data on grain yield $\left(\mathrm{g} \mathrm{plot}^{-1}\right)$ and 1000 seed weight (g) were collected on a plot basis. Grain yields recorded on a plot basis were converted to a hectare $\left(\mathrm{kg} \mathrm{ha}^{-1}\right)$ basis for statistical analyses. Separate and pooled analysis of variance over location was made according to the following standard methods using SAS computer software (SAS Institute, 1996).

Components due to genotype $\left(\sigma_{\mathrm{G}}^{2}\right)$, environment $\left(\sigma_{\mathrm{E}}^{2}\right)$, genotype by environment interaction $\left(\sigma_{\mathrm{GE}}{ }^{2}\right)$ variances, and broad-sense heritability $\left(h^{2}\right)$ and the expected genetic gain from selection (GA) were calculated from the separate and pooled analyses of variance by assuming various observed mean squares equal to their expected mean squares as shown in Table 2 (Singh and Chaudhary, 1985). The mean values of $h^{2}$ and GA from separate analysis of variance were averaged over locations for each experiment and then they were compared with values obtained from pooled analysis of variance of the same experiment.

Table 1. Multilocation faba bean variety trials grown in drained and waterlogged vertisols (1996-1999).

\begin{tabular}{llllll}
\hline Experiment & Year & No. of entries & Design & No. of reps & Location \\
\hline EXP 1 & 1996 & 24 & RCB & 2 & Ginchi and Enewari \\
EXP 2 & 1997 & 25 & Lattice & 2 & Ginchi, Enewari and Bichena \\
EXP 3 & 1997 & 17 & RCB & 3 & Ginchi, Enewari, Bichena and Sinja \\
EXP 4 & 1998 & 25 & Lattice & 2 & Ginchi and Enewari \\
EXP 5 & 1998 & 18 & RCB & 3 & Ginchi, Enewari, Bichena and Sinja \\
EXP 6 & 1999 & 25 & RCB & 2 & Ginchi and Sinja \\
EXP 7 & 1999 & 18 & RCB & 3 & Ginchi and Bichena \\
\hline
\end{tabular}

Table 2a. Separate analysis of variance followed in faba bean variety trials grown in drained and waterlogged Vertisols based on a replicated experiment under randomized complete block design.

\begin{tabular}{llll}
\hline Source of variation & Degree of freedom & Mean square $(\mathrm{MS})$ & Expected mean square $($ EMS) \\
\hline Replication & $\mathrm{r}-1$ & $\mathrm{MS} 1$ & $\sigma_{\mathrm{E}}{ }^{2}+\mathrm{g} \sigma_{\mathrm{r}}^{2}$ \\
Genotypes & $\mathrm{g}-1$ & $\mathrm{MS} 2$ & $\sigma_{\mathrm{E}}{ }^{2}+\mathrm{r}_{\mathrm{G}}{ }^{2}$ \\
Error & $(\mathrm{r}-1)(\mathrm{g}-1)$ & $\mathrm{MS} 3$ & $\sigma_{\mathrm{E}}{ }^{2}$ \\
\hline
\end{tabular}

Table 2b. Combined analysis of variance followed in faba bean variety trials grown under drained and waterlogged vertisols based on a replicated experiment under randomized complete block design.

\begin{tabular}{|c|c|c|c|}
\hline Source of variation & Degree of Freedom ${ }^{1}$ & Mean Square (MS) & Expected Mean Square (EMS) ${ }^{2}$ \\
\hline Locations & $1-1$ & MS1 & $\sigma_{\mathrm{e}}^{2}+\mathrm{r} \sigma_{\mathrm{gl}}{ }^{2}+\mathrm{gr} \sigma_{\mathrm{l}}^{2}$ \\
\hline Replications/location & $1(\mathrm{r}-1)$ & MS2 & $\sigma_{\mathrm{E}}^{2}+g \sigma_{\mathrm{r}}^{2}$ \\
\hline Genotypes & $g-1$ & MS3 & $\sigma_{\mathrm{E}}^{2}+\mathrm{r}_{\mathrm{gl}^{2}}{ }^{2}+\mathrm{rl}_{\mathrm{g}^{2}}^{2}$ \\
\hline Genotype x Environment & $(g-1)(1-1)$ & MS4 & $\sigma_{\mathrm{e}}^{2}+\mathrm{r}_{\mathrm{gl}^{2}}^{2}$ \\
\hline Error & $1(g-1)(r-1)$ & MS5 & $\sigma_{\mathrm{e}}^{2}$ \\
\hline
\end{tabular}

${ }^{1} l, r$, and $g$ are number of locations, replications and genotypes, respectively.

${ }^{2} \sigma_{e}^{2}, \sigma_{r}^{2}, \sigma_{l}^{2}, \sigma_{g}^{2}$, and $\sigma_{g l}^{2}$ are error, replication, location, genotypic and genotype $x$ location (or genotype by environment) interaction variances, respectively.

\section{Results and Discussion}

The comparison of average performances of grain yield and 1000 seed weight in each experiment on BBF and flatbeds clearly revealed that the magnitude of responses to environmental change (drainage) varied between the two traits (Table 4). On average, relative reductions (RR) on flatbeds compared to the ones on BBF were $17 \%$ for grain yield and only $1 \%$ for thousand seed weight. This indicates that grain yield was more sensitive to environmental change than thousand seed weight. Other authors also reported grain yield to be greatly influenced by environmental changes (Dantuma and Thompson, 1983; Lawes et al., 1983) and seed weight to be among the most stable components, least affected by changes in the environment (Dantuma and Thompson, 1983). 
Heritability and expected genetic gains of grain yield calculated from separate analysis of variance were higher compared to those calculated from pooled analysis of variance in all the cases. The average relative precision improvements (RPI) of pooled analysis of variance over separate analysis of variance, calculated as 1-[Value of pooled analysis/Value of separate analysis], were $66 \%$ for heritability and $83 \%$ for genetic gain on $\mathrm{BBF}$ and
$57 \%$ for heritability and $75 \%$ for genetic gain on flatbeds. However, lower differences were observed between values calculated from separate and pooled analysis of variance for thousand seed weight compared to grain yield. On average, RPI values were only $7 \%$ for heritability and $23 \%$ for genetic gain on BBF and $13 \%$ for heritability and $25 \%$ for genetic gain on flatbeds (Tables $5 \mathrm{a}$ and $\mathrm{b}$ ).

Table 3. Calculations of the components of variance $\left(\sigma_{\mathrm{g}}{ }^{2}, \sigma_{\mathrm{e}}{ }^{2}\right.$ and $\left.\sigma_{\mathrm{ge}}{ }^{2}\right)$, broad-sense heritability $\left(\mathrm{h}^{2}\right)$ and expected genetic advance (GA) from separate and pooled analyses of variance in faba bean variety trials grown in drained and waterlogged vertisols (1996-1999).

\begin{tabular}{|c|c|c|}
\hline Variance $^{1}$ & Separate analysis $^{2}$ & Pooled analysis \\
\hline$\sigma_{\mathrm{g}}^{2}$ & $\begin{array}{l}=\left[\left(\sigma_{\mathrm{e}}^{2}+\mathrm{r} \sigma_{\mathrm{g}}^{2}\right)-\sigma_{\mathrm{e}}^{2}\right] / \mathrm{r} \\
=\mathrm{MS} 2-\mathrm{MS} 3\end{array}$ & $\begin{array}{l}=\left[\left(\sigma_{\mathrm{e}}^{2}+\mathrm{r} \sigma_{\mathrm{gl}}{ }^{2}+\mathrm{rl} \sigma_{\mathrm{g}}^{2}\right)-\left(\sigma_{\mathrm{e}}^{2}+\mathrm{r}_{\mathrm{g}^{2}}{ }^{2}\right)\right] / \mathrm{rl} \\
=(\mathrm{MS} 3-\mathrm{MS} 4) / \mathrm{RL}\end{array}$ \\
\hline$\sigma_{\mathrm{e}^{2}}^{2}$ & $\begin{array}{l}=\sigma_{\mathrm{e}}^{2} \\
=\mathrm{MS} 3\end{array}$ & $\begin{array}{l}=\sigma_{\mathrm{e}}^{2} \\
=\mathrm{MS} 5\end{array}$ \\
\hline$\sigma_{\mathrm{ge}}{ }^{2}$ & - & $\begin{array}{l}=\left[\left(\sigma_{\mathrm{e}}^{2}+\mathrm{r} \sigma_{\mathrm{g}}^{2}\right)-\left(\sigma_{\mathrm{e}}^{2}\right)\right] / \mathrm{r} \\
=(\mathrm{MS} 4-\mathrm{MS} 5) / \mathrm{r}\end{array}$ \\
\hline$h^{2}$ & $\mathrm{~h}^{2}=\sigma_{\mathrm{g}}^{2} /\left[\sigma_{\mathrm{g}}^{2}+\sigma_{\mathrm{e}}{ }^{2} / \mathrm{r}\right]$ & $\sigma_{\mathrm{g}}^{2} /\left[\sigma_{\mathrm{g}}^{2}+\sigma_{\mathrm{ge}}{ }^{2} / 1+\sigma_{\mathrm{e}}^{2} / \mathrm{rl}\right]$ \\
\hline GA & $\delta . \sigma_{\mathrm{g} .} \mathrm{h}$ & $\delta . \sigma_{\mathrm{g}} \cdot \mathrm{h}$ \\
\hline
\end{tabular}

${ }^{1} b^{2}=$ beritability in the broad-sense, $G A=$ expected genetic gain from selection

${ }^{2} \delta=$ selection differential (assuming a standardized selection differential of 1, Falconer 1989),

$h=$ square root of heritability in the broad-sense and other components of the equations are described under Table $2 b$.

Table 4. Mean performances for grain yield $\left(\mathrm{kg} \mathrm{ha}^{-1}\right)$ and its determinants in faba bean variety trials grown in drained and waterlogged vertisols (1996-1999).

\begin{tabular}{|c|c|c|c|c|c|c|}
\hline \multirow[t]{2}{*}{ Experiment } & \multicolumn{3}{|c|}{ Thousand seed weight } & \multicolumn{3}{|c|}{ Grain yield $\left(\mathrm{kg} \mathrm{ha}^{-1}\right)$} \\
\hline & $\mathrm{BBF}$ & Flat & $\mathrm{RR}^{*}$ & $\mathrm{BBF}$ & Flat & RR \\
\hline EXP 1 & 284.88 & 284.26 & 0.00 & 1769.48 & 996.84 & 0.44 \\
\hline EXP 2 & 332.74 & 331.56 & 0.00 & 2209.79 & 2061.83 & 0.07 \\
\hline EXP 3 & 366.27 & 357.66 & 0.02 & 2567.5 & 2186.82 & 0.15 \\
\hline EXP 4 & 342.43 & 332.21 & 0.03 & 1461.00 & 1324.23 & 0.09 \\
\hline EXP 5 & 356.80 & 340.58 & 0.05 & 2354.83 & 1973.19 & 0.16 \\
\hline EXP 6 & 378.24 & 371.92 & 0.02 & 3085.23 & 2724.79 & 0.12 \\
\hline EXP 7 & 366.43 & 379.80 & -0.04 & 3210.99 & 2710.26 & 0.16 \\
\hline Mean & 346.83 & 342.57 & 0.01 & 2379.83 & 1996.85 & 0.17 \\
\hline
\end{tabular}

*RR is relative reductions, calculated as 1-(values under flat beds / values under BBF)

The magnitudes of heritabilities and expected genetic gains from selection calculated using separate analysis of variance for both grain yield and 1000 seed weight were plotted against values calculated using pooled analysis of variance. Linear regressions were adjusted to show the trends (Figures 1 and 2). There were weak interrelationships $\left(\mathrm{R}^{2}=0.00-0.37\right)$ between heritability and expected genetic gains of grain yield calculated from separate and pooled analyses of variance both on BBF and flatbeds in almost all cases (Figure 1). This indicates that heritability and expected genetic gains from selection calculated from separate and pooled analyses of variance were dissimilar. Normally, there should have been a perfect positive interrelationship between the two in order for values calculated from separate analysis of variance to serve as the measure of their counterparts calculated from pooled analyses of variance. The weak association could be due to the fact that genotype by environment interaction effects were confounded in the case of separate analysis of variance while they were included in estimations based on pooled analysis of variance. Thus, heritability and expected genetic gains calculated from separate analysis of variance were biased upwards, and this indicates that basing studies on genetic variability and effectiveness of selection on separate analysis of variance for grain yield could be misleading because of overestimation. This could be due to the use of broad-sense heritability which is composed of additive and non-additive gene effects. On the other hand, there were positive, strong associations $\left(\mathrm{R}^{2}=0.66-0.88\right)$ between the heritability and expected genetic gains calculated from separate and pooled analysis of variance for thousand seed weight (Figure 2). Genetic variability and effectiveness of selection determined from separate analysis of variance could be used for thousand seed weight with certain levels of uncertainty. 

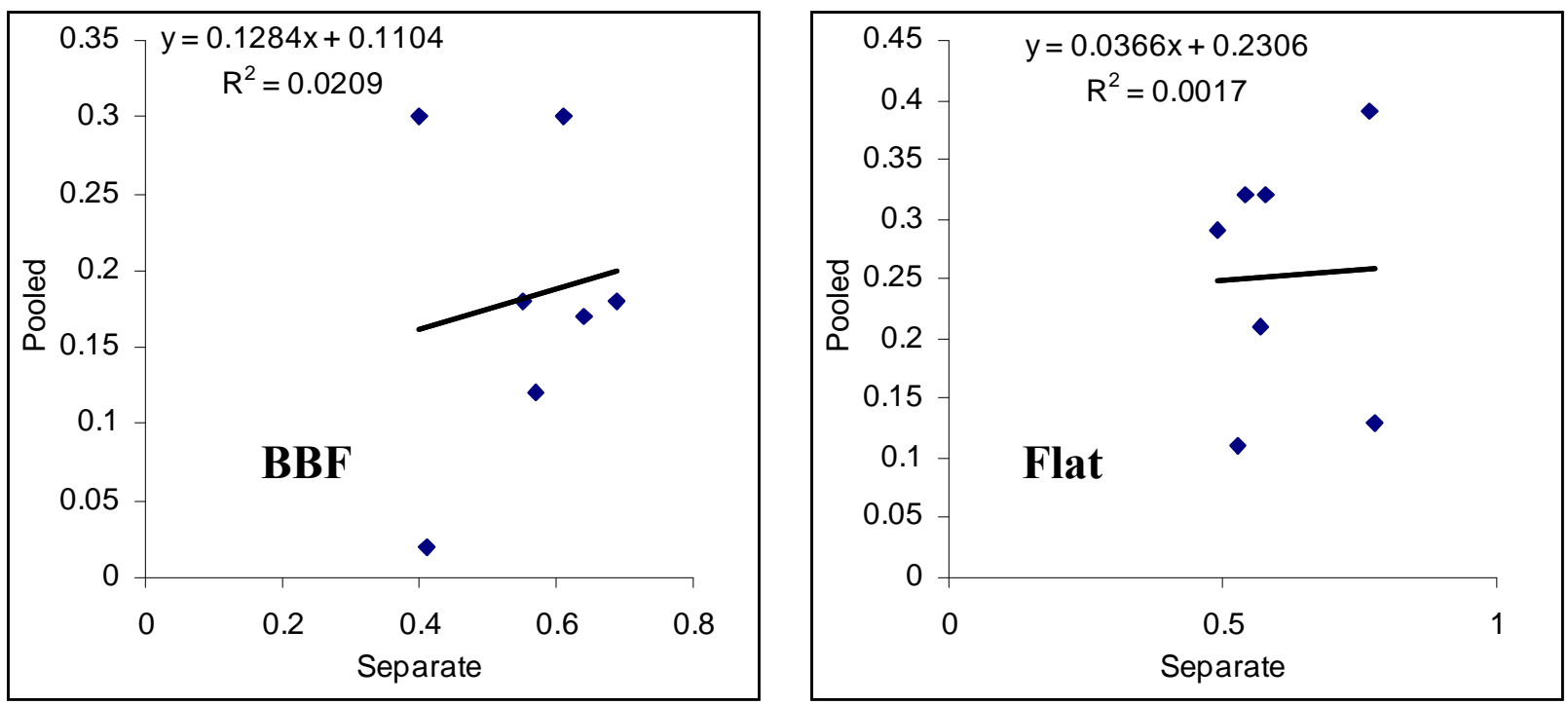

(A) Heritability
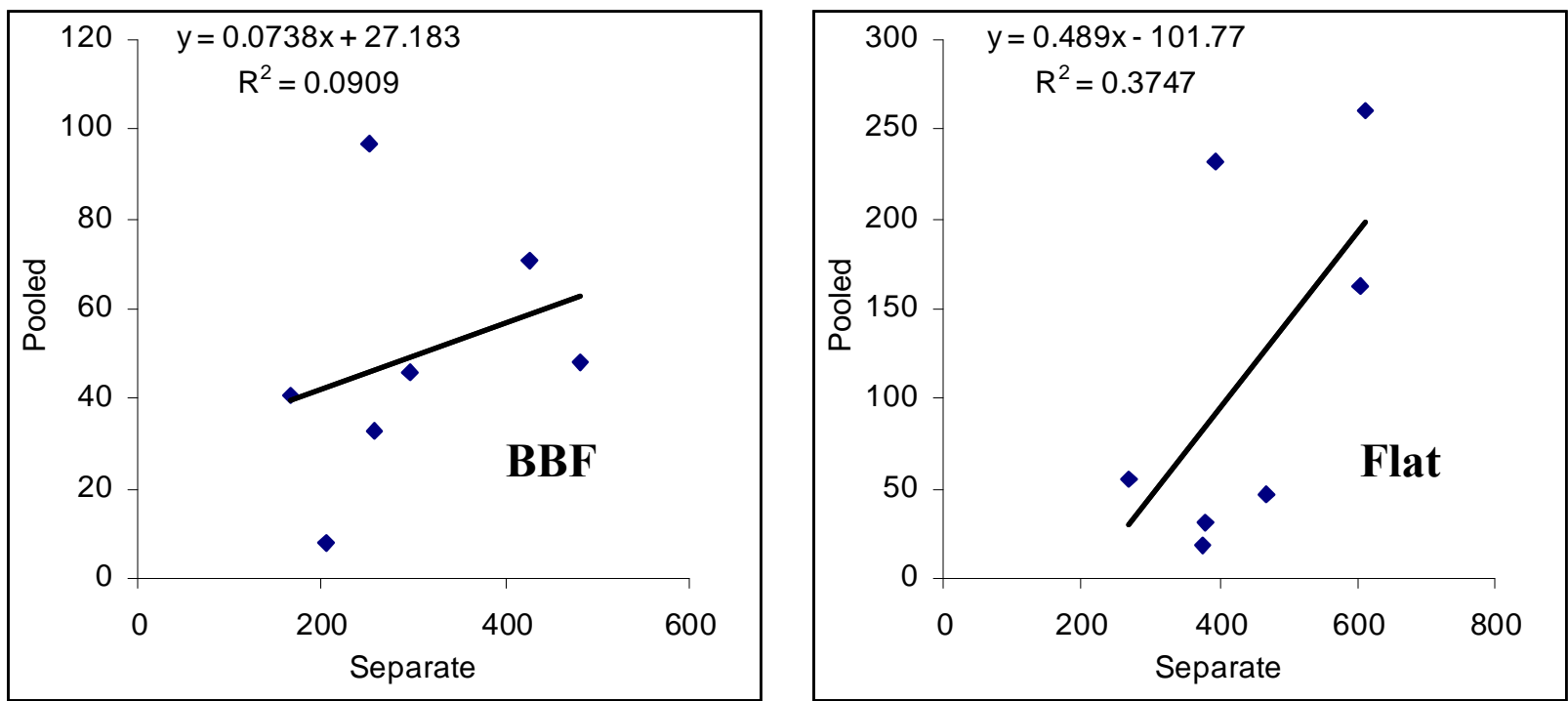

(B) Genetic gain

Figure 1. Joint plot of heritability and expected genetic gains for grain yield determined from separate and pooled analyses of variance in faba bean variety trials grown under drained and waterlogged vertisols (1996-1999). 

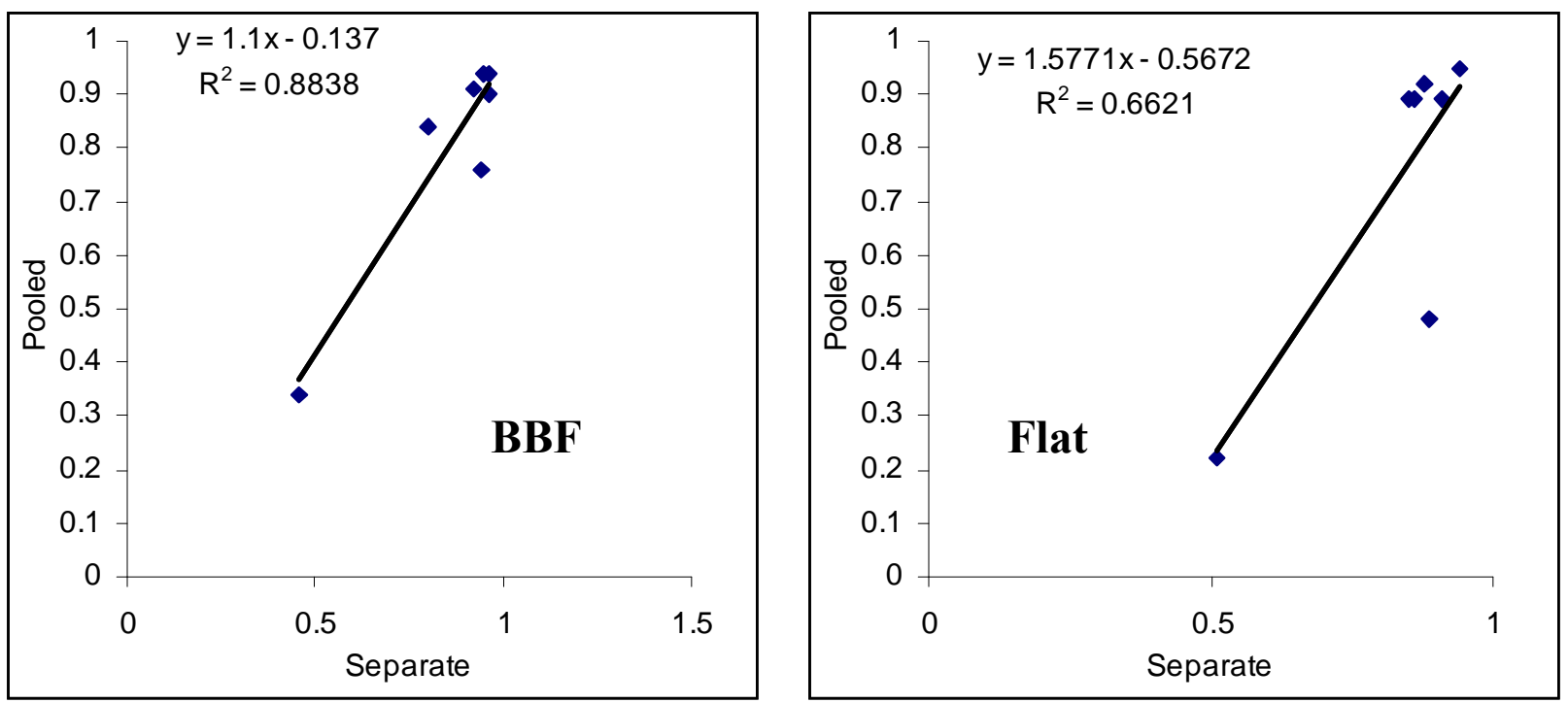

(A) Heritability
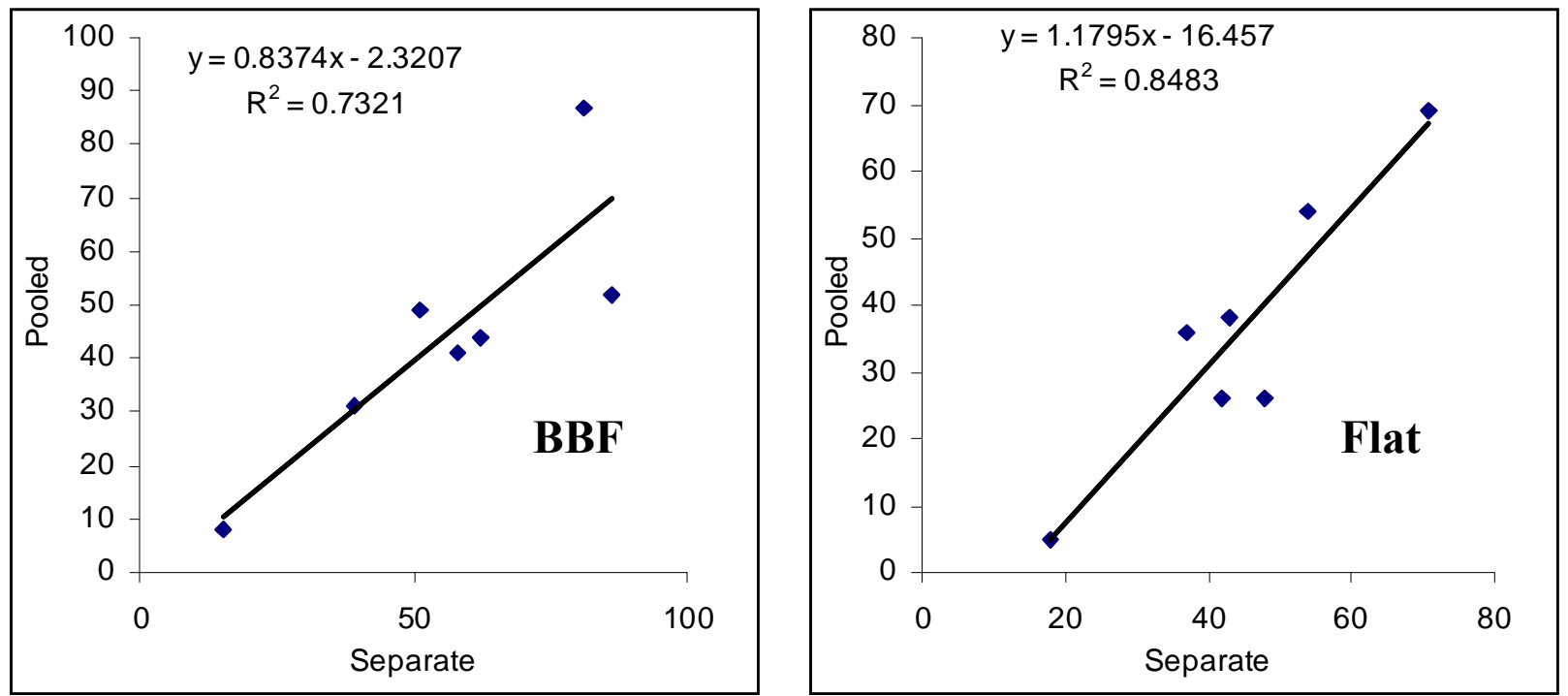

(B) Genetic advance

Figure 2. Joint plot of heritability and expected genetic gains for thousand seed weight determined from separate and pooled analyses of variance in faba bean variety trials grown under drained and waterlogged vertisols (1996-1999).

It also seems that heritability could be more safely determined from separate analysis of variance than expected genetic gains from selection. However, as this study did not consider genotype by environment interaction effects due to seasonal variation, the calculations could have affected even thousand seed weight if such interactions differed considerably from the genotype by environment interactions due to locations. Even though the relative importance of spatial variation over temporal variation was reported for faba bean variety trials in waterlogged vertisols of Ethiopia (Mussa and Gemechu, 2004), temporal variation may also sometimes be more influential than the former (Lawes et al., 1983; Mussa et al., 2003). 
Table 5a. Broad-sense heritability $\left(\mathrm{h}^{2}\right)$ and expected genetic gains (GA) for thousand seed weight (g) and grain yield (kg $\mathrm{ha}^{-1}$ ) calculated from separate analysis of variance averaged over location and pooled analysis of variance in faba bean variety trials grown under drained $(\mathrm{BBF})$ Vertisols.

\begin{tabular}{|c|c|c|c|c|c|c|}
\hline \multirow[t]{2}{*}{ Experiment } & \multicolumn{3}{|l|}{$h^{2}$} & \multicolumn{3}{|l|}{ GA } \\
\hline & $\begin{array}{l}\text { Separate } \\
\text { analysis }\end{array}$ & $\begin{array}{l}\text { Pooled } \\
\text { analysis }\end{array}$ & RPI* & Separate analysis & Pooled analysis & RPI \\
\hline \multicolumn{7}{|c|}{ Thousand seed weight } \\
\hline EXP 1 & 0.46 & 0.34 & 0.26 & 15 & 8 & 0.47 \\
\hline EXP 2 & 0.96 & 0.94 & 0.02 & 51 & 49 & 0.04 \\
\hline EXP 3 & 0.92 & 0.91 & 0.01 & 62 & 44 & 0.29 \\
\hline EXP 4 & 0.95 & 0.94 & 0.01 & 81 & 87 & -0.07 \\
\hline EXP 5 & 0.96 & 0.90 & 0.06 & 86 & 52 & 0.40 \\
\hline EXP 6 & 0.80 & 0.84 & -0.05 & 39 & 31 & 0.21 \\
\hline EXP 7 & 0.94 & 0.76 & 0.19 & 58 & 41 & 0.29 \\
\hline Mean & 0.86 & 0.80 & 0.07 & 56 & 45 & 0.23 \\
\hline \multicolumn{7}{|l|}{ Grain yield } \\
\hline EXP 1 & 0.57 & 0.12 & 0.79 & 258 & 33 & 0.87 \\
\hline EXP 2 & 0.61 & 0.30 & 0.51 & 251 & 97 & 0.61 \\
\hline EXP 3 & 0.40 & 0.30 & 0.25 & 166 & 41 & 0.75 \\
\hline EXP 4 & 0.55 & 0.18 & 0.67 & 296 & 46 & 0.84 \\
\hline EXP 5 & 0.64 & 0.17 & 0.73 & 482 & 48 & 0.90 \\
\hline EXP 6 & 0.41 & 0.02 & 0.95 & 204 & 8 & 0.96 \\
\hline EXP 7 & 0.69 & 0.18 & 0.74 & 425 & 71 & 0.83 \\
\hline Mean & 0.55 & 0.18 & 0.66 & 297 & 49 & 0.83 \\
\hline
\end{tabular}

*RPI $=$ relative precision improvement of pooled analysis over separate analysis of variance, calculated as 1-[ Value of pooled analysis/ Value of separate analysis]

Table 5b. Broad-sense heritability $\left(\mathrm{h}^{2}\right)$ and expected genetic gains (GA) for thousand seed weight (g) and grain yield (kg $\mathrm{ha}^{-1}$ ) calculated from separate analysis of variance averaged over location and pooled analysis of variance in faba bean variety trials grown under undrained (Flat) Vertisols.

\begin{tabular}{|c|c|c|c|c|c|c|}
\hline \multirow[t]{2}{*}{ Experiment } & \multicolumn{3}{|l|}{$h^{2}$} & \multicolumn{3}{|l|}{ GA } \\
\hline & $\begin{array}{l}\text { Separate } \\
\text { analysis }\end{array}$ & $\begin{array}{l}\text { Pooled } \\
\text { analysis }\end{array}$ & RPI* & Separate analysis & Pooled analysis & RPI \\
\hline \multicolumn{7}{|c|}{ Thousand seed weight } \\
\hline EXP 1 & 0.51 & 0.22 & 0.57 & 18 & 5 & 0.72 \\
\hline EXP 2 & 0.91 & 0.89 & 0.02 & 43 & 38 & 0.12 \\
\hline EXP 3 & 0.86 & 0.89 & -0.03 & 48 & 26 & 0.46 \\
\hline EXP 4 & 0.94 & 0.95 & -0.01 & 71 & 69 & 0.03 \\
\hline EXP 5 & 0.88 & 0.92 & -0.05 & 54 & 54 & 0.00 \\
\hline EXP 6 & 0.89 & 0.48 & 0.46 & 42 & 26 & 0.38 \\
\hline EXP 7 & 0.85 & 0.89 & -0.05 & 37 & 36 & 0.03 \\
\hline Mean & 0.83 & 0.75 & 0.13 & 45 & 36 & 0.25 \\
\hline \multicolumn{7}{|l|}{ Grain yield } \\
\hline EXP 1 & 0.57 & 0.21 & 0.63 & 270 & 55 & 0.80 \\
\hline EXP 2 & 0.77 & 0.39 & 0.49 & 613 & 261 & 0.57 \\
\hline EXP 3 & 0.58 & 0.32 & 0.45 & 379 & 31 & 0.92 \\
\hline EXP 4 & 0.78 & 0.13 & 0.83 & 469 & 47 & 0.90 \\
\hline EXP 5 & 0.53 & 0.11 & 0.79 & 377 & 19 & 0.95 \\
\hline EXP 6 & 0.54 & 0.32 & 0.41 & 395 & 232 & 0.41 \\
\hline EXP 7 & 0.49 & 0.29 & 0.41 & 606 & 163 & 0.73 \\
\hline Mean & $\overline{0.61}$ & 0.25 & 0.57 & 444 & 115 & 0.75 \\
\hline
\end{tabular}

*RPI $=$ relative precision improvement of pooled analysis over separate analysis of variance, calculated as 1-[ Value of pooled analysis] $V$ alue of separate analysis] 


\section{Conclusion}

This study clearly showed that, where environmental differences are great, as in drained and un-drained waterlogged Vertisols, it may be expected that genotype by environment interaction effect is also high. In such cases, care must be taken not to use statistical models that omit inclusion of the genotype by environment interaction effects unless otherwise proven that the performance of the given crop or the given trait is not considerably influenced by environmental fluctuations.

\section{Acknowledgments}

The authors wish to thank all the staff of the Highland Pulses Research Program at Holetta, Adet, Sinana and Sheno Agricultural Research Centers who managed the trials.

\section{References}

Allard, R.W. 1960. Principles of Plant Breeding. John Wiley and Sons, Inc., New York.

Asfaw, T., Tesfaye, G. and Beyene, D. 1994. Genetics and breeding of faba bean. In: Asfaw, T., Geletu, B., Saxena, M. C. and Solh, M. B. (eds.). Coos-season Food Legumes of Ethiopia. Proceeding of the first national cool-season food legumes review conference, 16-20 December 1993, Addis Ababa, Ethiopia. ICARDA/IAR. ICARDA, Syria. pp. 97-124.

Banziger, M. and Edmeades, G.O. 1997. Predicted productivity gains from breeding maize under stressed vs. non-stressed conditions. In: Ransom, J.K., Palmer, A.F.E., Zambezi, B.T., Mduruma, Z.O., Waddington, S.R., Pixley, K.V. and Jewell, D.C. (eds.). Maize Productivity Gains Through Research and Technology Dissemination: proceedings of the $5^{\text {th }}$ Eastern and Southern Africa Regional Maize Conference, held in Arusha, Tanzania, 3-7 June 1996. Addis Abeba, Ethiopia: CIMMYT. pp. 136140.

Briggs, F.N. and Knowles, P.F. 1967. Introduction to Plant Breeding, Reinhold Publishing Corporation, USA.

Dantuma, G. and Thompson, R. 1983. Whole crop physiology and yield components. In: Hebblethwaite, P.D. (eds.). The Faba Bean (Vicia faba L.). Great Britain, The University Press, Cambridge. pp. 143-158.

Gemechu, K. 1996. Variability and interrelationship of some metric characters in groundnut (Arachis bypogaea L.). M.Sc Thesis. Alemaya University of Agriculture, Ethiopia.

Gemechu, K., Belay, S. and Getinet, G. 1999. Genetic variability in groundnut. In: Sebil: Proceedings of the $8^{\text {th }}$ Annual conference of the Crop Science Society of Ethiopia, 26-27 Feb. 1997, IAR, Addis Abeba, Ethiopia. pp.42-47.
Gemechu, K. and Mussa, J. 2003. Faba Bean Breeding for Waterlogged Vertisols of Ethiopia. Research Report No. 46. Ethiopian Agricultural Research Organization (EARO), Addis Ababa, Ethiopia.

Lawes, D.A., Bond, D.A. and Poulsen, M.H. 1983. Classification, origin, breeding methods and objectives. In: Hebblethwaite, P.D. (eds.). The Faba Bean (Vicia faba L.), Great Britain, The University Press, Cambridge. pp. 23-76.

Mussa, J. and Gemechu, K. 2004. Classification of some waterlogged varietal testing environments on Ethiopian vertisols on the basis of grain yield response of faba bean genotypes. Ethiopian Journal of Natural Resources 6(1): 25-40.

Mussa, J., Tezera, W. and Gemechu, K. 2006. Review of Field Pea (Pisum sativum L.) Genetics and Breeding Research in Ethiopia. In: Kemal, A., Gemechu, K., Seid, A., Rajendra, M., Surendra, B., Khaled, M. and Halila, M.H. (eds.). Food and Forage Legumes of Ethiopia. Progress and prospects. Proceedings of a Workshop on Food and Forage Legumes. 22-26 Sept 2003, Addis Ababa, Ethiopia. ICARDA, Aleppo, Syria. ISBN 92-9127-185-4. pp. 351.

Picard, J. and Berthelem, P. 1980. A brief comment on yield stability and thousand grain weight in Vicia faba. FABIS 2: 20

Rosielle, A.A. and Hamblin. J. 1981. Theoretical aspects of selection for yield in stress and non-stress environments. Crop Science 21: 943-946.

SAS (Statistical Analysis System Institute). 1996. SAS/STAT guide for personal computers, version 6.12 edition. Cary, NC: SAS Institute Inc.

Simmonds, N.W. 1991. Selection for local adaptation in a plant breeding programme. Theory and Applied Genetics 82: 363-367.

Singh, B.D. 1990. Plant Beeding: Principles and Methods. Kalyani Publishers, New Delhi-Ludhiana.

Singh, R.K. and Chauhary, B.D. 1985. Bioemetrical Methods in Quantitative Genetic Analysis. Kalyani Publishers, New Delhi-Ludhiana.

Temesgen, A. 2002. Genetic divergence and association among quantitative traits in Tef [Eragrostis tef (Zucc.) Trotter] germplasm. M.Sc Thesis. Alemaya University of Agriculture, Ethiopia.

Tesfaye, G. 1999. Genetic variability and association of characters in some Ethiopian field pea (Pisum sativum L.) germplasm. M.Sc. Thesis. Alemaya University of Agriculture, Ethiopia.

Wondafrash, M. 2002. Variation and association among seed yield and associated traits in faba bean (Vicia faba L.) land races of Ethiopia under vertisol conditions. M.Sc. Thesis. Alemaya University, Ethiopia. 